\title{
Metal to semiconductor transition and phase stability of Ti1-xMgxNy alloys investigated by first-principles calculations
}

\author{
Björn Alling
}

\section{Linköping University Post Print}

\section{Tweet}

N.B.: When citing this work, cite the original article.

Original Publication:

Björn Alling, Metal to semiconductor transition and phase stability of Ti1-xMgxNy alloys investigated by first-principles calculations, 2014, Physical Review B. Condensed Matter and Materials Physics, (89), 8, 085112.

http://dx.doi.org/10.1103/PhysRevB.89.085112

Copyright: American Physical Society http://www.aps.org/

Postprint available at: Linköping University Electronic Press http://urn.kb.se/resolve?urn=urn:nbn:se:liu:diva-105755 


\title{
Metal to semiconductor transition and phase stability of $\operatorname{Ti}_{1-x} \operatorname{Mg}_{x} \mathrm{~N}_{y}$ alloys investigated by first-principles calculations
}

\author{
B. Alling* \\ Thin Film Physics Division, Department of Physics, Chemistry and Biology (IFM), Linköping University, SE-581 83 Linköping, Sweden
}

(Received 24 December 2013; published 13 February 2014)

\begin{abstract}
Titanium nitride based materials are applied in several technological applications owing to their stability at high temperatures, mechanical and optical properties, as well as good electrical conductivity. Here, I use theoretical first-principles methods to investigate the possibilities for a semiconducting state as well as the phase stability of $\mathrm{Ti}_{1-x} \mathrm{Mg}_{x} \mathrm{~N}_{y}$ ternary alloys and compounds. I demonstrate that $\mathrm{B} 1(\mathrm{NaCl})$ solid solutions of $\mathrm{Ti}_{1-x} \mathrm{Mg}_{x} \mathrm{~N}$ with $x \leqslant 0.5$ are thermodynamically stable with respect to all previously reported phases in the Ti-Mg-N system. For the composition $x=0.5$, an ordered $\mathrm{TiMgN}_{2}$ phase with an $\mathrm{L}_{1}$-type order of Ti and $\mathrm{Mg}$ on the metal sublattice is predicted to be the configurational ground state at low temperatures. Other ordered phases present in neighboring materials systems are considered but are found to be unstable. The electronic origin of the stability of the B1 structure solid solutions is identified. A metal to semiconductor transition is observed as the $\mathrm{Mg}$ content is increased to $x=0.5$. TiMgN 2 as well as disordered $\mathrm{Ti}_{0.5} \mathrm{Mg}_{0.5} \mathrm{~N}$ solid solution are investigated with hybrid functional calculations and predicted to be semiconductors with band gaps of $1.1 \mathrm{eV}$ and around $1.3 \mathrm{eV}$, respectively, the latter depending on the details of the $\mathrm{Ti}$ and $\mathrm{Mg}$ configuration.
\end{abstract}

DOI: 10.1103/PhysRevB.89.085112

PACS number(s): 71.20.Nr, 71.30.+h

\section{INTRODUCTION}

Thin films based on titanium nitride are used in several technological applications. In particular, hard protective coatings on cutting tools [1], diffusion barriers in microelectronics [2], decorative coatings [3], and coatings on bioinplants [4] are areas where TiN is applied owing to its hardness, electrical and optical properties, and biocompatibility. The properties of TiN have been further improved by alloying. The mixing of TiN with titanium carbide [5,6], other transition metal nitrides [7-10], silicon nitride [11-13], and most intesively, AlN [14-17], has been successfully employed and investigated. The metastable $\mathrm{Ti}_{1-x} \mathrm{Al}_{x} \mathrm{~N}$ thin film alloys are found to be superior to pure TiN coatings in terms of oxidation resistance [18] and hardness at high temperatures $[19,20]$. Using experimental and theoretical methods these improvements have been found to be connected to the phase stability and spinodal decomposition during operation [19-23], which in turn has been associated with the electronic structure of the alloys and its dependency on the configuration [21,24-27]. In parallel with the technological success, a significant research interest has resulted in thousands of scientific publications, in particular studies of $\mathrm{Ti}_{1-x} \mathrm{Al}_{x} \mathrm{~N}$, but also other ternary and related quaternary TiN-based coatings.

Despite this huge interest and the demonstrated possibility to improve TiN properties through alloying and electronic structure engineering, only a handful of investigations have considered the Ti-Mg-N system [28-32]. This is so even though $\mathrm{Mg}$, with two valence electron less than Ti but a quite similar atomic size, can be expected to give rise to interesting alloying physics effects in TiN. In particular, judging from the valence of $\mathrm{Mg}$ and $\mathrm{Ti}$, it might be possible to design semiconducting alloys at intermediate compositions. Such alloys could possibly offer an alternative to expensive $\mathrm{ScN}$,

*bjoal@ifm.liu.se recently suggested for thermoelectric $[33,34]$ and piezoelectric applications [35,36].

Furthermore, hypothetical B1 structure $\mathrm{MgN}$ has been predicted to display an unusual type of magnetism [37], but the possibility to synthesize it in pure form seems slim as the stable stoichiometry is $\mathrm{Mg}_{3} \mathrm{~N}_{2}$. Instead, alloying of $\mathrm{Mg}$ into a nitride stable in the B1 structure, such as TiN, seems like a promising root to approach the predicted $\mathrm{MgN}$ properties.

No ternary Ti-Mg-N phases are reported in the equilibrium phase diagram literature [38]. Despite this, Banakh et al. demonstrated that it was possible to grow solid solutions of B1 structure $\mathrm{Ti}_{1-x} \mathrm{Mg}_{x} \mathrm{~N}$ using reactive magnetron sputtering [28]. The $\mathrm{Ti}_{1-x} \mathrm{Mg}_{x} \mathrm{~N}$ coatings where found to display an attractive change in color from gold-colored TiN through pink and violet to gray, depending on the composition [28]. Similar findings were reported by Fenker et al. who also reported excellent corrosion resistance of $\mathrm{Ti}_{1-x} \mathrm{Mg}_{x} \mathrm{~N}$ coatings on steel [30] and improved oxidation resistance in hot air [29]. Hodroj et al. employed reactive hybrid cathodic arc-magnetron sputtering synthesis techniques to grow $\mathrm{Ti}_{1-x} \mathrm{Mg}_{x} \mathrm{~N}$ coatings and found similar results [31]. Nanoindentation measurements of hardness indicated a constant [31], or moderately decreased [29], hardness as compared to pure TiN for $x \leqslant 0.35-0.37$ while a substantial decrease was observed for $x=0.51$ and 0.67 [29].

Recently Onder et al. showed that $\mathrm{Ti}_{1-x} \mathrm{Mg}_{x} \mathrm{~N}$ alloys are promising candidates for bioinplant coatings [32]. The investigated composition, $\mathrm{Ti}_{0.936} \mathrm{Mg}_{0.064} \mathrm{~N}$ synthesized by cathodic arc evaporation, was found to be superior to pure TiN coatings in promoting nucleation and growth of magnesium-substituted hydroxyapatite on the coating surface when submerged in simulated body fluids [32].

The possibility for future applications of Ti-Mg-N materials as decorative, corrosion resistant coatings or biocoatings depends on which synthesis routs and methods that can be used to produce the alloys. In particular, it is not known whether these $\mathrm{Ti}_{1-x} \mathrm{Mg}_{x} \mathrm{~N}$ alloys are equilibrium phases or 
if they belong to the same family as $\mathrm{Ti}_{1-x} \mathrm{Al}_{x} \mathrm{~N}$ and are only metastable, on the verge of phase separation as soon as diffusion is activated. If stable, bulk equilibrium synthesis, as well as high-temperature chemical vapor deposition methods could open for several areas of applications. If instead metastable, physical vapor deposited thin films, similar to the reports discussed above, might be the only synthesis route. Furthermore, the electronic structure of the $\mathrm{Ti}_{1-x} \mathrm{Mg}_{x} \mathrm{~N}$, and whether or not a semiconducting state can be expected at intermediate compositions is still unknown.

In this work, theoretical first-principles methods within the density functional theory (DFT) framework and alloy theory are used to investigate the phase stability of $\mathrm{Ti}_{1-x} \mathrm{Mg}_{x} \mathrm{~N}_{y}$ materials with respect to all other reported phases in the Ti-Mg-N system, as well as hypothetical phases with the structures obtained from reported phases in neighboring systems. Particular focus is given to the possibility for metal sublattice ordering and nitrogen sublattice off-stoichiometry of the B1 structure $\mathrm{Ti}_{1-x} \mathrm{Mg}_{x} \mathrm{~N}_{1-\delta}$ alloy phases. Structural parameters are compared with experiments and the calculated electronic structure, both using standard exchange-correlations approximations and hybrid functional calculations, are discussed in context of possibilities for semiconducting behavior, the observed phase stability, and the experimental reports of optical and electrical properties.

\section{CALCULATIONAL DETAILS}

To calculate total energies of the different studied phases, first-principles calculations were employed using the projector augmented wave method [39] as implemented in the Vienna ab initio simulation package (VASP) [40-42]. Electronic exchange correlation effects were modeled using the generalized gradient approximation [43]. To obtain reliable values of the electronic band gap of $\mathrm{TiMgN}_{2}$ and $\mathrm{Ti}_{0.5} \mathrm{Mg}_{0.5} \mathrm{~N}$ alloys, hybrid functional calculations according to Heyd, Scuseria, and Emzerhof (HSE06) [44] were performed. The plane-wave energy cutoff was $400 \mathrm{eV}$. In order to model configurationally disordered alloys, calculations using a special quasirandom structure (SQS) [45] approach were used with a disordered metal sublattice on the B1 underlying lattice. To obtain equilibrium lattice spacings and bulk moduli the structures suggested in Ref. [21] with 48 and 64 atoms depending on composition were used. To obtain converged values of the alloy total energy and to investigate nitrogen off-stoichiometry, 128 atoms SQS structures were used. For the SQS calculations, all internal atomic positions were fully relaxed while the cell shape were kept at the underlying B1 geometry.

Ordered configurations focused on the composition $\mathrm{Ti}_{0.5} \mathrm{Mg}_{0.5} \mathrm{~N}$ were selected in a similar fashion as in Ref. [22] using structures of 4 to 16 metal atoms created by extending the unit cell of the B1 structure in the [001], [110], [111], and [211] direction and ensuring that they had unique values of shortrange order parameters on the first two coordination shells. To obtain better reliability of the configurational energetics close to the ideal disordered solid solutions, 180 randomly generated configurations of 24 and 36 metal atom supercells were also considered. For illustrative purposes, selected ordered structures were also calculated for $x=0.125,0.25,0.375$.
The energies on a grid of seven volumes were used for each composition and the equation of states were obtained using fitting to a modified Morse curve [46]. For the calculations of ordered $\mathrm{Ti}_{1-x} \mathrm{Mg}_{x} \mathrm{~N}$ alloy configurations as well as all other $\mathrm{Ti}_{1-x} \mathrm{Mg}_{x} \mathrm{~N}_{y}$ compounds, internal atomic positions and the cell shape were fully relaxed for each considered volume. The sampling of the Brillouin zone was done with a MonkhorstPack scheme [47] with the number of $k$ points depending on the number of atoms in each cell, but with the total energy differing with less than $0.4 \mathrm{meV}$ per atom with respect to fully converged calculations obtained for a representative number of test cases. To visualize the electronic density of states a 0.1-eV Methfessel-Paxton-type smearing was used in the calculations but to obtain the values for the band gap without smearing effects, the tetrahedron method was used. Inspired by the discussion in Ref. [37], spin polarization was allowed in all calculations. The nitrogen chemical potential was taken as half the energy calculated for the $\mathrm{N}_{2}$ molecule, corresponding to nitrogen rich conditions. However, the effect of high temperature and low nitrogen pressure is discussed in the text following the approach of Hao et al. [48].

To obtain the configurational interactions of the generalized Ising-type [49] for the composition $\mathrm{Ti}_{0.5} \mathrm{Mg}_{0.5} \mathrm{~N}$, the unified cluster expansion procedure derived in Ref. [22] was used. First, pair interactions on the first 25 coordination shells were derived using the generalized perturbation method (GPM) [50,51]. With this method, also 16 different three-site interactions were derived corresponding to small triangle clusters where the shortest side were nearest or next-nearest metal neighbors, second shortest was not longer then third metal neighbors, and the third side were not longer than ninth metal neighbor. Furthermore 16 four-site interactions were derived corresponding to small tetrahedra clusters were no side were longer than the fifth nearest metal neighbor distance, except the four-site line cluster along the fcc nearestneighbor direction. Then, local lattice relaxations and shortrange electrostatic screening effects were taken into account using concentration dependent Connolly-Williams (CW) [52] type cluster expansion of the differences between ordering energies of the GPM based potentials and direct first-principles calculations of 131 ordered $\mathrm{Ti}_{0.5} \mathrm{Mg}_{0.5} \mathrm{~N}$ structures, which have energies lower than our 128-atoms SQS structure. Several different sets of clusters were considered in $\mathrm{CW}$ expansions and the set was chosen for which the square differences of the Ising and first-principles energies of 16 structures that were not included in the fitting procedure were the smallest.

The obtained interactions were used in configurational Monte Carlo simulations using the Metropolis [53] algorithm and using simulation boxes of $16 \times 16 \times 16$ conventional cubic cells to obtain temperature dependent configurational thermodynamics, including the ordering temperature.

\section{RESULTS AND DISCUSSION}

\section{A. Structural parameters of $\mathbf{B 1} \mathbf{T i}_{1-x} \mathbf{M g}_{x} \mathbf{N}$ solid solutions}

The starting point of the investigations are the solid solutions of $\mathrm{Ti}_{1-x} \mathrm{Mg}_{x} \mathrm{~N}_{1-\delta}$ in the cubic B1 structure as 


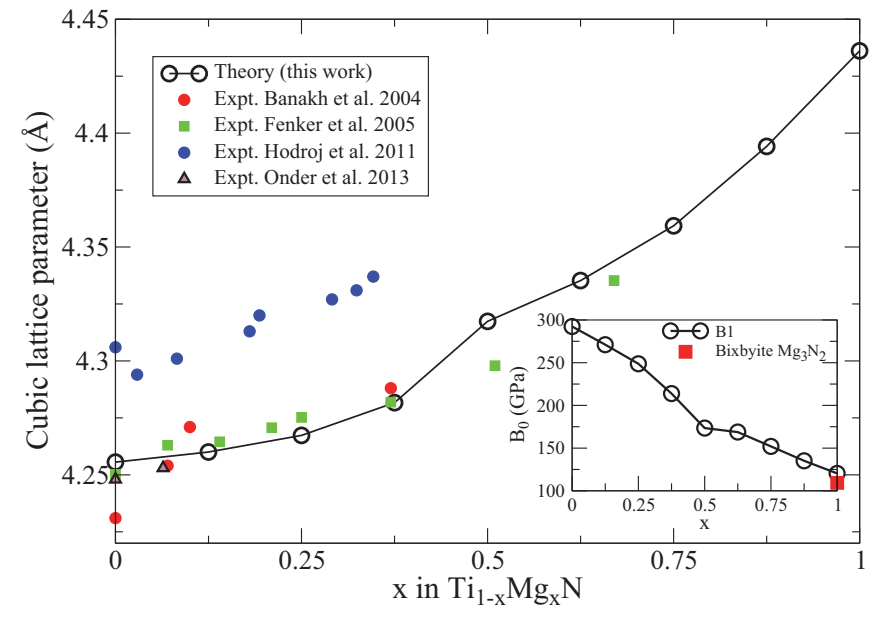

FIG. 1. (Color online) Calculated lattice parameters of $\mathrm{Ti}_{1-x} \mathrm{Mg}_{x} \mathrm{~N}$ solid solutions in the $\mathrm{B} 1$ structure as a function of $\mathrm{Mg}$ content. The experiments by Banakh et al. [28], Fenker et al. [29], Hodroj et al. [31], and Onder et al. [32] are shown for comparison. The inset shows the calculated bulk modulus of the alloys as well as the calculated value for the $\mathrm{Mg}_{3} \mathrm{~N}_{2}$ in its equilibrium inverse bixbyite structure.

reported in the experiments discussed above [28-32]. The calculated equilibrium lattice spacing and bulk moduli of nitrogen stoichiometric $\mathrm{Ti}_{1-x} \mathrm{Mg}_{x} \mathrm{~N}$ B1 structure alloys are shown in Fig. 1 and compared to the experimentally reported values of lattice parameters. The calculated lattice parameter for pure TiN, $4.255 \AA$, is in good agreement with the experimentally well established room-temperature bulk value of $4.24 \AA$ [54]. Upon $\mathrm{Mg}$ addition, the lattice spacing is increasing. The increase is not linear but displays a distinct negative deviation from Vegards rule. Furthermore, the lattice parameter as well as the bulk modulus, display a kink with respect to composition at $x=0.5$, possibly indicating two different types of bonding regimes. The bulk modulus decrease monotonously with $\mathrm{Mg}$ content. The bulk modulus of pure TiN is found to be $292 \mathrm{GPa}$ in line with previous comparable calculations [55]. At the composition $\mathrm{Ti}_{0.5} \mathrm{Mg}_{0.5} \mathrm{~N}$, the value has decreased to $173 \mathrm{GPa}$ while pure B1 structure $\mathrm{MgN}$ is found to have a bulk modulus of $120 \mathrm{GPa}$, not much higher then that of our calculated value for inverse bixbyite $\mathrm{Mg}_{3} \mathrm{~N}_{2}$ of $109 \mathrm{GPa}$.

The calculated lattice parameters compare well with the experimental values regarding the increasing trend with $\mathrm{MgN}$ content. Also the negative deviation from Vegard's rule can be noted in the work of Fenker et al. [29] and Hodroj et al. [31] although less distinct as compared to the calculations. The absolute values of the lattice spacings in the work of Hodroj et al. are shifted to slightly higher values as compared to both the calculations and the other experiments indicating residual tensile stress in their coatings. The alloys with the highest reported $\mathrm{Mg}$-content, the samples with the compositions $x=0.51$ and 0.67 displays a slightly lower lattice spacing as compared to the calculations. A possible explanation could be a partial phase separation, that the $\mathrm{Mg}$ content in the B1 phase is slightly lower than the global $\mathrm{Mg}$ composition. A corresponding case was found for the B1 structure $\mathrm{Sc}_{0.27} \mathrm{Al}_{0.73} \mathrm{~N}$ alloy in Ref. [56]. Another possible explanation is nitrogen under-stoichiometry as the $\mathrm{N}$ content of the films were reported to decrease [29]. Unfortunately, the energy dispersive $\mathrm{x}$-ray spectroscopy measurements of the composition of light elements, such as N, has limited accuracy, but the trend of decreasing $\mathrm{N}$ content with increasing $\mathrm{Mg}$ content should be trustworthy. It is worth noting that such decrease in nitrogen content would also be the result if the films contain $\mathrm{Mg}_{3} \mathrm{~N}_{2}$ based domains.

\section{B. Nitrogen substoichiometry of $\mathrm{B1} \mathrm{Ti}_{1-x} \mathrm{Mg}_{x} \mathrm{~N}_{1-\delta}$ solid solutions}

The next step in the investigation is a study of the tendency for nitrogen substoichiometry of $\mathrm{Ti}_{1-x} \mathrm{Mg}_{x} \mathrm{~N}_{1-\delta}$ solid solutions. The starting point is the calculation of nitrogen vacancy formation energies according to

$\Delta E_{\mathrm{N}_{\mathrm{vac}}}^{i}(x)=E\left(\mathrm{Ti}_{1-x} \mathrm{Mg}_{x} \mathrm{~N}_{1-\delta^{i}}\right)-E\left(\mathrm{Ti}_{1-x} \mathrm{Mg}_{x} \mathrm{~N}\right)+\frac{1}{2} E\left(\mathrm{~N}_{2}\right)$,

where $E\left(\mathrm{Ti}_{1-x} \mathrm{Mg}_{x} \mathrm{~N}_{1-\delta^{i}}\right)$ is the energy of the supercell with Mg content $x$ including a nitrogen vacancy on the particular site $i, E\left(\operatorname{Ti}_{1-x} \mathrm{Mg}_{x} \mathrm{~N}\right)$ is the same supercell without nitrogen vacancy and $E\left(\mathrm{~N}_{2}\right)$ is the calculated energy of a nitrogen molecule at $0 \mathrm{~K}$. In a real PVD deposition experiment, the temperature is typically several hundred degrees Celsius, $200^{\circ}$ and $300^{\circ}$ is reported by Fenker et al. [29] and Hodroj et al. [31], respectively. Furthermore, the nitrogen partial pressure is typically in the range from a few pascals to $10^{-2} \mathrm{~Pa}[29,31,32]$. Under such conditions, following the discussion by Hao et al. [48] the nitrogen chemical potential should be almost $1 \mathrm{eV}$ lower than half of the $\mathrm{N}_{2}$ molecule energy. However, it should be noted that PVD is a nonequilibrium technique were also atomic $\mathrm{N}$ can be present and increase the effective nitrogen chemical potential during film growth.

The values of $\Delta E_{\mathrm{N}_{\mathrm{vac}}}^{i}(x)$ are shown in Fig. 2. For pure TiN, where all the 64 nitrogen sites are equivalent, a value of $\Delta E_{\mathrm{N}_{\mathrm{vac}}}(0)=2.42 \mathrm{eV}$ is obtained. This value is in good

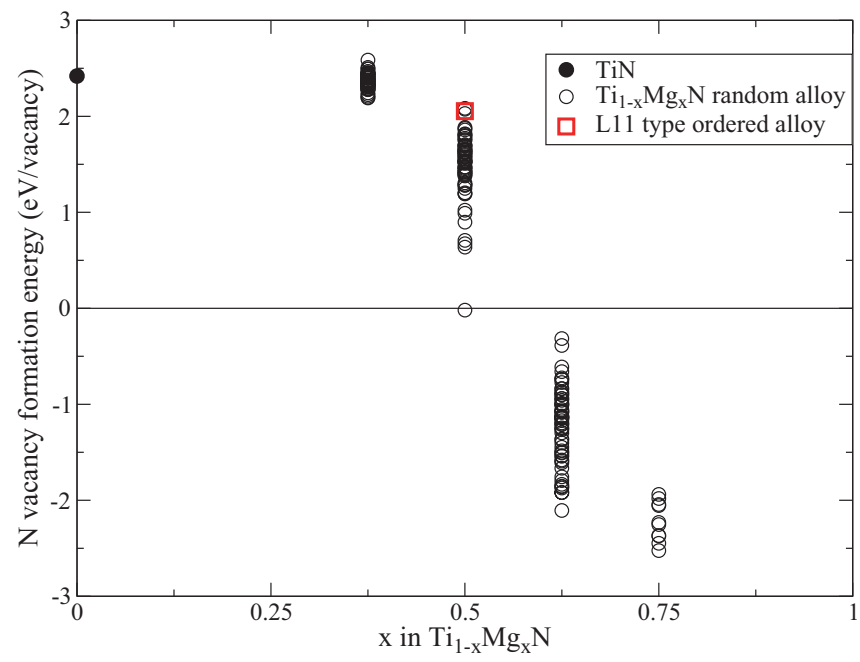

FIG. 2. (Color online) Calculated nitrogen vacancy formation energies for different local environments as a function of the $\mathrm{Mg}$ content of $\mathrm{B} 1$ structure $\mathrm{Ti}_{1-x} \mathrm{Mg}_{x} \mathrm{~N}_{1-\delta^{i}}$ solid solutions. 
agreement with previous calculations of the nitrogen formation energy in TiN, e.g., $2.41 \mathrm{eV}$ found by Tsetseris et al. [57]. As expected from the magnesium nitride having the $\mathrm{Mg}_{3} \mathrm{~N}_{2}$ stoichiometry, the values of $\Delta E_{\mathrm{N}_{\mathrm{vac}}}^{i}(x)$ decrease upon increasing $\mathrm{Mg}$ content. However, even at $x=0.375$, the mean value of the individual nitrogen vacancies at different sites in the SQS supercell is still as high as $2.37 \mathrm{eV}$. The lowest individual value of $\Delta E_{\mathrm{N}_{\mathrm{vac}}}^{i}(0.375)$ is $2.19 \mathrm{eV}$, while the highest value is $2.59 \mathrm{eV}$. This can be interpreted as if the tendency for substoichiometry is only slightly higher in $\mathrm{Ti}_{0.625} \mathrm{Mg}_{0.375} \mathrm{~N}$ alloys as compared to pure TiN where the latter can be grown at close to stoichiometric compositions using reactive magnetron sputtering or reactive cathodic arc evaporation techniques.

At the composition $x=0.5$, the situation is altered. The mean value of $\Delta E_{\mathrm{N}_{\mathrm{vac}}}^{i}(0.5)$ is now $1.48 \mathrm{eV}$, almost $1 \mathrm{eV}$ lower than the case of pure TiN. Furthermore, the individual configurations strongly influence the vacancy formation energies and one of the 64 nitrogen sites shows a slightly negative vacancy formation energy, $-0.05 \mathrm{eV}$ indicating a tendency for spontaneous nitrogen vacancy formation of a fraction of the lattice sites. The overall trend is that sites with the lowest values of $\Delta E_{\mathrm{N}_{\mathrm{vac}}}^{i}(0.5)$ correspond to nitrogen atoms surrounded by several $\mathrm{Mg}$ atoms. However, the situation is more complex than just a linear function of the nearest-neighbor composition as the site with negative formation energy has four $\mathrm{Mg}$ atoms as nearest neighbors, while there exist $\mathrm{N}$ sites in our supercell that have five and six Mg nearest neighbors while still demonstrating positive vacancy formation energy. It is worth noting that the preference of nitrogen vacancies for $\mathrm{Mg}$-rich local environments are different from the corresponding case for $\mathrm{Ti}_{1-x} \mathrm{Al}_{x} \mathrm{~N}_{1-\delta}$ alloys where instead vacancies were found to prefer Ti-rich environments [58,59] in the limit close to stoichiometric conditions. As a comparison, the nitrogen vacancy formation energy was also calculated in a 32-formula unit supercell with an $\mathrm{L}_{1}$-type ordered metal sublattice, a structure, which will be discussed below. In this case, were all $\mathrm{N}$ sites are equivalent, the vacancy formation energy is as high as $2.05 \mathrm{eV}$. This shows that metal sublattice ordering is a mechanism that compete with nitrogen understoichiometry in this system.

For the composition $x=0.625$, all vacancy formation energies are negative with a mean value of $-1.22 \mathrm{eV}$. The sample of ten calculated vacancies at $x=0.75$ is even more negative in value with a mean of $-2.22 \mathrm{eV}$. These calculations strongly indicating that all existing B1 structure $\mathrm{Ti}_{1-x} \mathrm{Mg}_{x} \mathrm{~N}_{1-\delta}$ alloys with $x>0.5$ ought to be understoichiometric in nitrogen.

The above discussion would still be valid if a nitrogen chemical potential that is $1 \mathrm{eV}$ lower is considered. However, at the composition $x=0.5$, ten percent of the nitrogen lattice site would then have a negative vacancy formation energy, indication a considerable tendency for understoichiometry at this composition if the growth temperature is high, or the nitrogen pressure is low.

Here, it is interesting to also make a comparison with the isostructural TiC system, which is isovalent with $\mathrm{Ti}_{0.5} \mathrm{Mg}_{0.5} \mathrm{~N}$. In $\mathrm{TiC}$, which is a metallic compound, understoichiometry of carbon is practically impossible to avoid in equilibrium as graphite appears before the B1 structure is fully carbon stoichiometric [60]. However, two distinct differences to $\mathrm{TiC}$ in the present nitride system is the gas form of the competing nitrogen phase and the electronic character, the latter to be discussed below.

\section{Mixing thermodynamics of $\mathrm{B} 1 \mathrm{Ti}_{1-x} \mathrm{Mg}_{x} \mathrm{~N}_{1-\delta}$}

The next step in our investigation is to analyze the thermodynamic phase stability of the $\mathrm{B} 1$ structure $\mathrm{Ti}_{1-x} \mathrm{Mg}_{x} \mathrm{~N}_{1-\delta}$ alloys with respect to the relevant competing phases in the $\mathrm{Ti}^{-}$ $\mathrm{Mg}-\mathrm{N}$ phase diagram. B1 structure TiN is a thermodynamically stable nitride, it is stable over a considerable composition window with both substoichiometry and overstoichiometry in nitrogen although substoichiometry is by far the most usual in magnetron sputtering and arc evaporation synthesis. As far as I am aware, no experimental synthesis of a $\mathrm{Ti}_{3} \mathrm{~N}_{4}$ phase has been reported. A nitrogen poor $\mathrm{Ti}_{2} \mathrm{~N}$ phase is also stable. On the magnesium nitride side, only $\mathrm{Mg}_{3} \mathrm{~N}_{2}$ phases has been reported to be stable, where the inverse bixbyite structure is found to be stable at ambient conditions [61]. As mentioned above, I am not aware of any equilibrium bulk synthesis of any ternary Ti-Mg-N compounds. Furthermore, the binary Ti-Mg phase diagram does not contain any intermetallic phases or alloys.

Figure 3 shows the calculated mixing enthalpy of B1 structure $\mathrm{Ti}_{1-x} \mathrm{Mg}_{x} \mathrm{~N}_{1-\delta}$ alloys with respect to $\mathrm{B} 1$ structure TiN at $x=0$ and a combination of inverse bixbyite $\mathrm{Mg}_{3} \mathrm{~N}_{2}$ and nitrogen molecules at $x=1$. In the cases where understoichiometric alloys are considered, nitrogen molecules are used to balance the $\mathrm{N}$ content. Thus the mixing enthalpies are calculated at zero pressure conditions according to

$$
\begin{aligned}
\Delta H(x)= & a E\left(\mathrm{Ti}_{1-x} \mathrm{Mg}_{x} \mathrm{~N}_{1-\delta}\right)+\delta \frac{1}{2} E\left(\mathrm{~N}_{2}\right) \\
& -(1-x) E(\mathrm{TiN})-x \frac{E\left(\mathrm{Mg}_{3} \mathrm{~N}_{2}+\frac{1}{2} \mathrm{~N}_{2}\right)}{3},
\end{aligned}
$$

and given per $\mathrm{Ti}_{1-x} \mathrm{Mg}_{x} \mathrm{~N}$ formula unit.

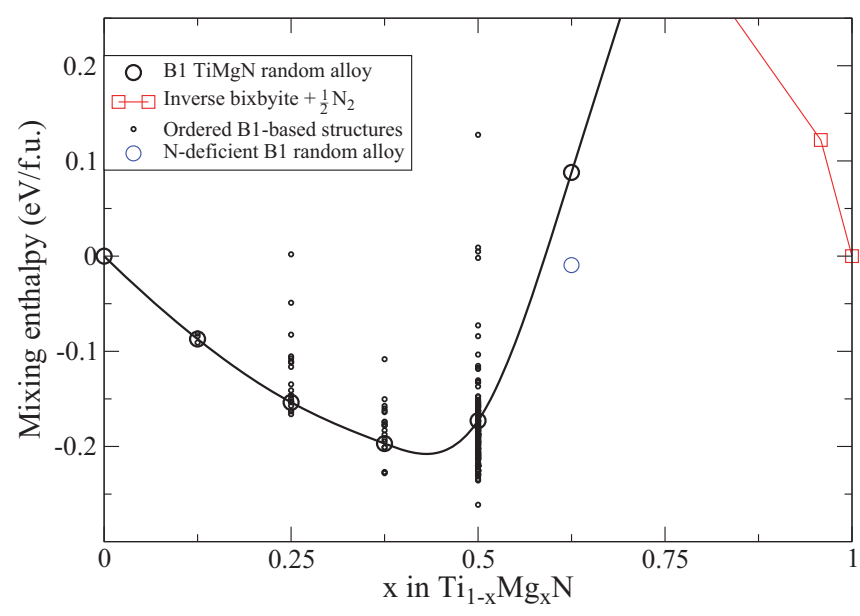

FIG. 3. (Color online) Calculated zero-pressure mixing enthalpies of B1 structure $\mathrm{Ti}_{1-x} \mathrm{Mg}_{x} \mathrm{~N}_{1-\delta}$ alloys with respect to $\mathrm{B} 1$ structure TiN and a combination of inverse bixbyite $\mathrm{Mg}_{3} \mathrm{~N}_{2}$ and $\mathrm{N}_{2}$ molecules. Both disordered and various ordered B1-derived phases are shown. The line connecting the data points for disordered solid solutions is a guide for the eye. Ti solutions into bixbyite $\mathrm{Mg}_{3} \mathrm{~N}_{2}$ is also shown for comparison. 
The figure shows that the enthalpies for disordered B1 structure $\mathrm{Ti}_{1-x} \mathrm{Mg}_{x} \mathrm{~N}$ alloys are negative for $0<x \lesssim 0.59$. For higher $\mathrm{Mg}$ content, the mixing enthalpies of the stoichiometric B1 structure solid solutions become positive. If a commontangent construction were made for the disordered B1 structure solutions and bixbyite $\mathrm{Mg}_{3} \mathrm{~N}_{2}+\frac{1}{2} \mathrm{~N}_{2}$, one would conclude that the $\mathrm{B} 1$ structure $\mathrm{Ti}_{1-x} \mathrm{Mg}_{x} \mathrm{~N}$ alloys were thermodynamically stable for $x \leqslant 0.46$. However, taking the possibility of metal sublattice ordering into account, it is apparent that also ordered compounds at $x=0.5$ can be stable.

Since it was found in the previous section that B1 structure solid solutions with $x>0.5$ ought to be understoichiometric, the mixing enthalpies of several different B1 structure $\mathrm{Ti}_{0.375} \mathrm{Mg}_{0.625} \mathrm{~N}_{0.922}$ and $\mathrm{Ti}_{0.375} \mathrm{Mg}_{0.625} \mathrm{~N}_{0.906}$ alloys were calculated. These compositions correspond to five or six $\mathrm{N}$ vacancies out of the $64 \mathrm{~N}$ sites in our supercells, which is approximately a linear interpolation between a metal-to-nitrogen composition of $1: 1$ at $x=0.5$ and $1: \frac{2}{3}$ at $x=1$. The lowest mixing enthalpy, according to Eq. (2), of these nitrogen substoichiometric compositions is shown in Fig. 3. Even though the mixing enthalpies of this substoichiometric alloy is below the corresponding stoichiometric case, it is still unfavorable with respect to decomposition into ordered or disordered $\mathrm{Ti}_{0.5} \mathrm{Mg}_{0.5} \mathrm{~N}$ alloys and $\mathrm{Mg}_{3} \mathrm{~N}_{2}$ (balanced with $\mathrm{N}_{2}$ ). Substitution of $\mathrm{Mg}$ for $\mathrm{Ti}$ in inverse bixbyite $\mathrm{Mg}_{3} \mathrm{~N}_{2}$ is found to be highly unfavorable and is not likely to be of relevance for the phase stability of thes alloys.

\section{Configurational thermodynamics of $\mathrm{B1} \mathrm{Ti}_{0.5} \mathrm{Mg}_{0.5} \mathrm{~N}$}

To reveal the relative stability of ordered and disordered $\mathrm{Ti}_{0.5} \mathrm{Mg}_{0.5} \mathrm{~N}$ phases the unified cluster expansion method [22] was used to derive configurational interactions of generalized Ising-type as described in Sec. II above. The generalized perturbation method potentials were complemented with structure inversion correction of the pair interactions on the coordination shells number $1,2,4,8$, and 20 , three different four-site clusters involving only nearest and next-nearest metal neighbors, as well as the configurational independent energy for ideally random $\mathrm{Ti}_{0.5} \mathrm{Mg}_{0.5} \mathrm{~N}$. The obtained two-, three-, and four-site interactions were used in a Monte Carlo simulation of the configurational order-disorder transition

The simulation resulted in a phase transition between a disordered solid solution and an ordered structure at a temperature of $T_{c}=950 \mathrm{~K}$ as revealed by a peak in the configurational specific heat. The Monte Carlo derived structure can be viewed as a $\mathrm{B} 1$ structure counterpart to either the $\mathrm{L} 1_{1}$ or $\mathrm{D} 4$ ordering on the fcc metal sublattice. These two structures have configurations with identical pair- and three-site correlation functions for all coordination shells and differ only in some of the four-site correlation functions and larger many-site clusters. As the four-site configurational interactions that differ between $\mathrm{L} 1_{1}$ and $\mathrm{D} 4$ structures are relatively weak in this system, the critical temperature is only marginally influenced by which of the two ordered phases that appear. In our firstprinciples calculations, the $\mathrm{L}_{1}$-type ordering is just below the D4 order in energy, they differ with about $1 \mathrm{meV}$ per formula unit, and the $\mathrm{L} 1_{1}$ are thus predicted as the configurational ground state of B1 structure $\mathrm{Ti}_{0.5} \mathrm{Mg}_{0.5} \mathrm{~N}$. For comparison, a mean-field estimate of the transition temperature based on the energy difference between the $\mathrm{B} 1-\mathrm{L} 1_{1}$ structure and the ideally random alloy obtained from the $V_{0}(x=0.5)$ value of the cluster expansion is $T_{c}^{\mathrm{MF}}=1272 \mathrm{~K}$.

The $\mathrm{L}_{1}$-type of metal sublattice ordering on the $\mathrm{B} 1$ lattice, often described by the $\alpha-\mathrm{NaFeO}_{2}$ or $\mathrm{NaCrS}_{2}$ systems as prototypes, has previously been observed experimentally for $\mathrm{TiWN}_{2}$ [8] and $\mathrm{CeSrN}_{2}$ [62] compounds, and predicted to be the configurational ground state also for $\mathrm{ZrGdN}_{2}$ [63].

\section{E. Phase stability of ordered $\mathrm{T}_{1-x} \operatorname{Mg}_{x} \mathrm{~N}_{y}$ phases}

In the discussion above, only the experimentally known phases has been considered as competing phases to the B1 structure $\mathrm{Ti}_{1-x} \mathrm{Mg}_{x} \mathrm{~N}$ random alloys and the $\mathrm{L}_{1}$-type ordered B1 $\mathrm{TiMgN}_{2}$ alloy. In order to investigate if yet other not previously observed phases could be competitive in the Ti-Mg$\mathrm{N}$ system, two alternative paths were used to select candidate structures. First, to investigate the $\mathrm{TiMgN}_{2}$ stoichiometry, a search for $\mathrm{ABN}_{2}$ structures, where $\mathrm{A}$ and $\mathrm{B}$ are metals or nonmetals while $\mathrm{N}$ is nitrogen, were performed in the inorganic crystal structure database (ICSD) [64]. More than 35 different trial crystal structures were identified in this way taking into account that some of the structures could result in two different phases depending on the placement of $\mathrm{Ti}$ and $\mathrm{Mg}$ atoms on the respective sublattices.

Table I shows the energies of the six $\mathrm{TiMgN}_{2}$ structures with lowest energy. The energy per atom with respect to the $\mathrm{B} 1-\mathrm{L} 1_{1}$ structure is shown together with the example nitride system in which they have been reported.

Even in the search in this wider group of candidate structures, the $\mathrm{B} 1-\mathrm{L}_{1}$-type structure has lowest energy for $\mathrm{TiMgN} \mathrm{M}_{2}$. The structure reported for $\mathrm{ZnGeN}_{2}$ and $\mathrm{MgSiN}_{2}$ phases, also referred to as $\beta-\mathrm{NaFeO}_{2}$-type structure, is $0.032 \mathrm{eV} /$ atom higher in energy. However, during the lattice relaxation of this structure for $\mathrm{TiMgN}_{2}$ the local atomic positions change in a similar way as when $\mathrm{ScN}$ is relaxed from wurtzite to a layered hexagonal phase [36]. The $\mathrm{SrSiN}_{2}$-type structure is $0.044 \mathrm{eV} /$ atom higher in energy than the $\mathrm{B} 1-\mathrm{L} 1_{1}$ structure. The structure of $\mathrm{LiUN}_{2}$, the inverse MAX-phase structure of, e.g., $\mathrm{ScTaN}_{2}$ [65], and the structure of $\mathrm{LiPN}_{2}$, also referred to as $\mathrm{KCoO}_{2}$-type structure, as well as all other considered cases, are even higher in energy.

TABLE I. Calculated total energies of $\mathrm{TiMgN}_{2}$ in the six different structures inspired by other $\mathrm{ABN}_{2}$ phases and found to be lowest in energy.

\begin{tabular}{lcc}
\hline \hline \multicolumn{2}{c}{$\mathrm{TiMgN}_{2}$} \\
\hline ICSD & $\Delta E(\mathrm{eV} /$ atom $)$ & Nitride examples \\
\hline 95805 & 0 & $\mathrm{SrCeN}_{2}, \mathrm{TiWN}_{2}$ \\
$\left(\mathrm{~B} 1-\mathrm{L} 1_{1}\right)$ & & \\
15144 & 0.032 & $\mathrm{ZnGeN}_{2}, \mathrm{MgSiN}_{2}$ \\
170270 & 0.044 & $\mathrm{SrSiN}_{2}$ \\
98663 & 0.059 & $\mathrm{LiUN}_{2}$ \\
25704 & 0.085 & $\mathrm{ScTaN}_{2}$, inverse-MAX $_{\text {LiPN }}$ \\
32713 & 0.125 & $\mathrm{LiPN}_{2}$ \\
\hline \hline
\end{tabular}




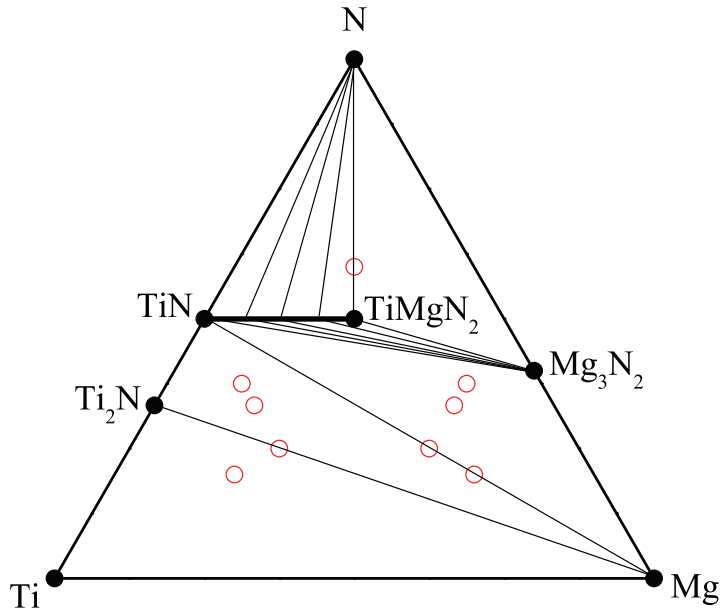

FIG. 4. (Color online) Calculated 0-K phase diagram of Ti-MgN. Stable phases are noted with black circles while considered but unstable phases are noted with open red circles. The thick line connecting $\mathrm{TiN}$ and $\mathrm{TiMgN}_{2}$ indicates the stability of a series of ordered B1 based compounds that are likely to disorder and form a solid solution single phase field also at low temperatures.

As a last verification step of the stability of $\mathrm{TiMgN}_{2}$, I search for possibly relevant competing ternary $\mathrm{Ti}-\mathrm{Mg}-\mathrm{N}$ phases based on other stoichiometries with structures that are observed in related ternary systems. The perovskite related structure of $\mathrm{MgTiO}_{3}$ is tested for $\mathrm{MgTiN}_{3}$, the MAX-phases observed for $\mathrm{Ti}_{2} \mathrm{AlN}, \mathrm{Ti}_{3} \mathrm{SiC}_{2}$, and $\mathrm{Ti}_{4} \mathrm{AlN}_{3}[66,67]$ are tested for $\mathrm{Ti}_{2} \mathrm{MgN}$, $\mathrm{Ti}_{3} \mathrm{MgN}_{2}, \mathrm{Ti}_{4} \mathrm{MgN}_{3}, \mathrm{Mg}_{2} \mathrm{TiN}, \mathrm{Mg}_{3} \mathrm{TiN}_{2}, \mathrm{Mg}_{4} \mathrm{TiN}_{3}$, and the inverse perovskite observed in, e.g., $\mathrm{Sc}_{3} \mathrm{AlN}[68,69]$ is tested for $\mathrm{Ti}_{3} \mathrm{MgN}$ and $\mathrm{Mg}_{3} \mathrm{TiN}$.

All these phases turns out to be unstable with respect to decomposition into combinations of the reported binary phases, pure elements, and in the case of $\mathrm{MgTiN}_{3}$, into $\mathrm{N}_{2}$ gas and the $\mathrm{B} 1-\mathrm{L} 1_{1} \mathrm{TiMgN}_{2}$ compound predicted to be stable in this work.

Based on the phase stability investigations of the above compounds, the $0 \mathrm{~K}$ phase diagram shown in Fig. 4 is predicted. According to the calculations, at intermediate metal content and low nitrogen content, the $\mathrm{Ti}_{2} \mathrm{~N}$ is the dominant nitride phase. At higher nitrogen content all $\mathrm{Ti}$ is bonded in a mixture of $\mathrm{Ti}_{2} \mathrm{~N}$ and $\mathrm{TiN}$ while $\mathrm{Mg}$ metal is still an equilibrium phase. $\mathrm{Mg}_{3} \mathrm{~N}_{2}$ is an equilibrium phase at even higher nitrogen content in the $\mathrm{Mg}$-rich compositions. The $\mathrm{TiMgN}_{2}$ compound is in equilibrium at very nitrogen- and magnesium-rich compositions. It is worth noting that a mixture of TiN and $\mathrm{Mg}_{3} \mathrm{~N}_{2}$ is not predicted to result in a ternary nitride. If such a mixture is subject to extra addition of nitrogen, gradually more $\mathrm{Mg}$ is solved into $\mathrm{B} 1$ related phases forming eventually the stoichiometric $\mathrm{TiMgN}_{2}$ phase.

\section{F. Electronic structure}

The phase stability of other multicomponent nitrides has previously been explained using the electronic structure [24,70,71]. In Fig. 5, the electronic density of states (DOS) of the $\mathrm{B} 1 \mathrm{Ti}_{1-x} \mathrm{Mg}_{x} \mathrm{~N}(0 \leqslant x \leqslant 0.5)$ alloys are shown. For comparison, the DOS of the hypothetical $\mathrm{B} 1 \mathrm{MgN}$ is also displayed in its ferromagnetic configuration.

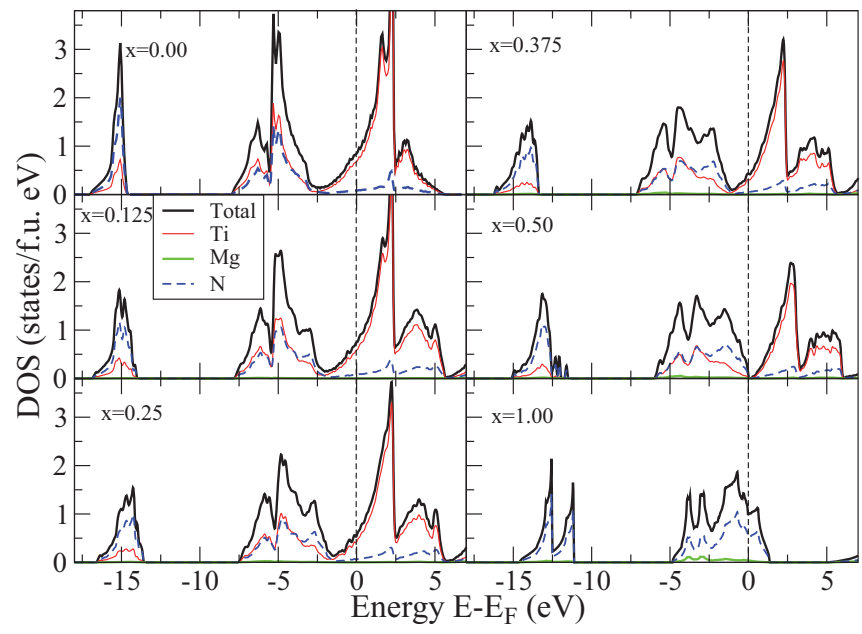

FIG. 5. (Color online) Calculated electronic density of states of $\mathrm{Ti}_{1-x} \mathrm{Mg}_{x} \mathrm{~N}$ solid solutions in the $\mathrm{B} 1$ structure for $0 \leqslant x \leqslant 0.5$. For comparison, the hypothetical $\mathrm{B} 1 \mathrm{MgN}$ is also shown in its ferromagnetic configuration.

The electronic structure of pure TiN has been studied in details in the past [5,72-74] and my results are in agreement with those reports: at energies around $15 \mathrm{eV}$ below $E_{F}$, the nitrogen $2 s$ semicore state is seen. At energies between 7.5 and $2.5 \mathrm{eV}$ below $E_{F}$, a so-called bonding state is seen. This state is a hybridization between nitrogen $2 p$ electrons and titanium $3 d$ electrons with $e_{g}$ symmetry. There is also an inmixture of $\mathrm{Ti} 4 s$ electron character. Around $E_{F}$ and up to about $2.5 \mathrm{eV}$ above, the so-called nonbonding state is seen. This state is composed mostly of Ti $3 d$ electrons with $t_{2 g}$ symmetry that do not hybridize strongly with the nitrogen $2 p$ electrons due to the octahedral coordination in the B1 structure. On the other hand, they hybridize to some extent with the electron of other Ti atoms with the same symmetry. The antibonding counterpart to the bonding states, composed mostly of Ti $3 d$ electrons with $e_{g}$ symmetry is centered around $3 \mathrm{eV}$ above $E_{F}$. It is important to note that TiN has seven valence electrons while only six can be accommodated in the bonding state. Thus the nonbonding state is partially occupied turning TiN into a metallic system.

Distinct differences can be noted when comparing TiN with the hypothetical B1 MgN phase. First, the latter lacks the states related to the Ti $3 d$ electrons. Furthermore, an ionic-type electronic structure can be assumed as the bonding state below $E_{F}$ is dominated by nitrogen character in contrast to the more covalent case of TiN. Six valence electrons are needed to fill the bonding state but $\mathrm{MgN}$ has only five, leaving part of the state unoccupied. A clear signature of the spin splitting, discussed in details by Droghetti et al. [37], can also be seen in the form of a doubling of the DOS peaks of nitrogen character. I suggest that the unoccupied part of the bonding state in $\mathrm{B} 1 \mathrm{MgN}$ is the qualitative explanation to the stability of the $\mathrm{B} 1 \mathrm{Ti}_{1-x} \mathrm{Mg}_{x} \mathrm{~N}$ alloys.

As $\mathrm{Mg}$ is substituting $\mathrm{Ti}$ in TiN, a part of the Ti electrons can be transferred from energetically rather unfavorable nonbonding states into the more favorable bonding states left empty around $\mathrm{Mg}$ atoms. This trend can, indeed, be seen in the panels showing the alloys of composition $0.125 \leqslant x \leqslant 0.5$ 
were the nonbonding Ti state is gradually emptied of electrons. Another effect that can be noted is that the overlap of the bonding and nonbonding states are gradually reduced which leaves the system $\mathrm{Ti}_{0.5} \mathrm{Mg}_{0.5} \mathrm{~N}$ as a semiconductor with $E_{F}$ positioned in a small band gap. The decrease of the overlap has its origin in the breaking of $\mathrm{Ti}$-Ti bonds upon $\mathrm{Mg}$ addition, an effect also seen in $\mathrm{Ti}_{1-x} \mathrm{Al}_{x} \mathrm{~N}$ [21]. In $\mathrm{Ti}_{1-x} \mathrm{Al}_{x} \mathrm{~N}$ this mechanism is suggested to be the reason behind the strong driving force for spinodal decomposition [21]. However, in the present case, with one less electron of $\mathrm{Mg}$ as compared to $\mathrm{Al}$, the possibility to redistribute $\mathrm{Ti}$ electrons into the bonding state is dominating over the loss of Ti-Ti bonds, resulting in a thermodynamically stable $\mathrm{Ti}_{1-x} \mathrm{Mg}_{x} \mathrm{~N}$ alloy for $x \leqslant 0.5$.

The decrease of electron states at $E_{F}$, responsible for the free-electron-like contribution to the optical properties of the material, is in line with what has been suggested in previous experimental work [28,29]. The shift of the Fermi level with respect to the nonbonding and bonding state is likely also related to the distinct change in color with composition observed experimentally [28,29].

The observation of the appearance of semiconducting character at the composition $x=0.5$ is interesting and deserves further investigations. This is so as TiN is known to be a good metallic electrical conductor and its alloys has therefore previously not been considered for semiconductor applications. TiC, with the same number of valence electrons as the $\mathrm{Ti}_{0.5} \mathrm{Mg}_{0.5} \mathrm{~N}$ composition, is also a metallic conductor. On the other hand, the neighboring scandium nitride, also with the same number of valence electrons, is a semiconductor with an indirect band gap of just below $1 \mathrm{eV}$ [75]. The band gaps derived from the calculated Kohn-Sham eigenvalues obtained within standard GGA calculations are known to underestimate experimental values. In order to obtain a more reliable predictions of the band-gap energies of the $\mathrm{Ti}_{0.5} \mathrm{Mg}_{0.5} \mathrm{~N}$ composition, calculations using the HSE06 [44] hybrid functional were employed, both for the $\mathrm{B} 1-\mathrm{L} 1_{1}$ ordered ground-state configuration and for the 48 atom SQS modeling disordered $\mathrm{Ti}_{0.5} \mathrm{Mg}_{0.5} \mathrm{~N}$. The HSE06 hybrid functional has been demonstrated to reproduce experimental band gaps, e.g., for $\mathrm{ScN}$ [34], quite well. Table II shows the calculated band gaps using both GGA-PBE and HSE06 functionals. In the case of the larger 128 atoms SQS, the use of the HSE06 functionals is too computationally demanding for the present work. The HSE06 band gaps are 1.11 and $1.33 \mathrm{eV}$ for the ordered and disordered configurations, respectively. However, it should be noted that the details of the configuration in the disordered state

TABLE II. Calculated electronic band gap of $\mathrm{Ti}_{0.5} \mathrm{Mg}_{0.5} \mathrm{~N}$ alloys modeled with two different sizes of SQS and the B1-L1 $1_{1}$ ordered $\mathrm{TiMgN}_{2}$ ground-state configuration using the PBE-GGA and HSE06 functionals.

\begin{tabular}{lcc}
\hline \hline & \multicolumn{2}{c}{ Band gap (eV) } \\
\cline { 2 - 3 } Configuration & GGA-PBE & HSE06 \\
\hline SQS 128 atoms & 0.22 & - \\
SQS 48 atoms & 0.45 & 1.33 \\
B1-L1 1 & 0.22 & 1.11 \\
\hline \hline
\end{tabular}

do influence the band gap as can bee seen by the difference in GGA-calculated band gap between the two SQS sizes. The semiconducting character of $\mathrm{Ti}_{0.5} \mathrm{Mg}_{0.5} \mathrm{~N}$ still remains to be proven experimentally, but it can be noted that a considerable increase in resistivity upon $\mathrm{Mg}$ addition to $\mathrm{TiN}$ were found by Hodroj et al. [31], but the possibly semiconducting composition was not investigated in that work. The possibility for a semiconductor behavior in $\mathrm{Ti}_{0.5} \mathrm{Mg}_{0.5} \mathrm{~N}$ motivates more detailed futures studies. In particular, the material is potential candidate to substitutes expensive $\mathrm{ScN}$ in piezoelectric $[35,36]$ and thermoelectric applications [33,34]. A material with a band gap in the range 1.1-1.3 eV also deserves to be further investigated for photovoltaics applications.

\section{CONCLUSIONS}

I have used theoretical methods to investigate the phase stability, structural and electronic properties of Ti-Mg-N phases. I have found that $\mathrm{Ti}_{1-x} \mathrm{Mg}_{x} \mathrm{~N}$ alloys in the cubic B1 structure and $x \leqslant 0.5$ are thermodynamically stable with respect to all previously reported phases in the Ti-Mg-N system, as well as with respect to ordered phases inspired by compounds in related ternary systems. For compositions with higher Mg content, I have not found any nitride phases that are stable with respect to decomposition into $\mathrm{B} 1 \mathrm{Ti}_{0.5} \mathrm{Mg}_{0.5} \mathrm{~N}_{1-\delta}$ alloys, inverse bixbyite $\mathrm{Mg}_{3} \mathrm{~N}_{2}$ and $\mathrm{N}_{2}$ gas. Thus I predict that the experimentally observed alloys with $x \leqslant 0.5$ are actually thermodynamically stable, while the single sample reported with higher $\mathrm{Mg}$ content is metastable and possible to synthesize as phase separation is suppressed due to lack of $\mathrm{Ti}$ and $\mathrm{Mg}$ diffusion during the low-temperature growth. An ordered $\mathrm{TiMgN}_{2}$ compound with the B1 counterpart to $\mathrm{L1}_{1}$ ( $\mathrm{CuPt}$ ) type ordering of $\mathrm{Ti}$ and $\mathrm{Mg}$ atoms is found to be the configurational ground state at $x=0.5$. Using the unified cluster expansion method and Monte Carlo simulations, the ordering temperature is predicted to be $950 \mathrm{~K}$. The stability of the alloys as well as the drastic change in color reported experimentally can be understood from the calculated electronic density of states where it is shown that electrons of nonbonding Ti $3 d t_{2 g}$ character are transferred to electron deficient bonding states in proximity to $\mathrm{Mg}$ atoms. Hybrid functional calculations suggest that the $\mathrm{Ti}_{0.5} \mathrm{Mg}_{0.5} \mathrm{~N}$ alloys and compounds are semiconducting with a band gap of between 1.11 to $1.33 \mathrm{eV}$ depending on the configuration. These findings of $\mathrm{Mg}$ as a stable alloying component in TiN with the possibility to obtain a semiconducting state broadens the perspective of electronic structure and phase stability design of multifunctional TiN-based coatings.

\section{ACKNOWLEDGMENTS}

H. Fager is acknowledged for useful discussions. Financial support by the Swedish Research Council (VR) through the young researcher Grant No. 621-2011-4417 is gratefully acknowledged. The simulations were carried out using supercomputer resources provided by the Swedish national infrastructure for computing (SNIC) carried out at the National supercomputer center (NSC) and the Center for high performance computing (PDC). 
[1] P. H. Mayrhofer, C. Mitterer, L. Hultman, and H. Clemens, Prog. Mater. Sci. 51, 1032 (2006).

[2] C. Y. Ting, J. Vac. Sci. Technol. 21, 14 (1982).

[3] P. Roquiny, F. Bodart, and G. Terwagne, Surf. Coat. Technol. 116-119, 278 (1999).

[4] B. Subramanian, C. V. Muraleedharan, R. Ananthakumar, and M. Jayachandran, Surf. Coat. Technol. 205, 5014 (2011).

[5] S. H. Jhi and J. Ihm, Phys. Rev. B 56, 13826 (1997).

[6] S.-H. Jhi, J. Ihm, S. Louie, and M. Cohen, Nature (London) 399, 132 (1999).

[7] H. Randhawa, P. C. Johnson, and R. Cunningham, J. Vac. Sci. Technol. A 6, 2136 (1988).

[8] F. Tian, J. D’ Arcy-Gall, T. Y. Lee, M. Sardela, D. Gall, I. Petrov, and J. E. Greene, J. Vac. Sci. Technol. A 21, 140 (2003).

[9] B. Alling, Phys. Rev. B 82, 054408 (2010).

[10] D. G. Sangiovanni, V. Chirita, and L. Hultman, Phys. Rev. B 81, 104107 (2010).

[11] S. Hao, B. Delley, and C. Stampfl, Phys. Rev. B 74, 035402 (2006).

[12] L. Hultman, J. Bareno, A. Flink, H. Söderberg, K. Larsson, V. Petrova, M. Oden, J. E. Greene, and I. Petrov, Phys. Rev. B 75, 155437 (2007).

[13] R. F. Zhang and S. Veprek, Phys. Rev. B 76, 174105 (2007).

[14] G. Beensh-Marchwicka, L. Kròl-Stepniewska, and W. Posadowski, Thin Solid Films 82, 313 (1981).

[15] O. Knotek, M. Böhmer, and T. Leyendecker, J. Vac. Sci. Technol. A 4, 2695 (1986).

[16] A. Hörling, L. Hultman, M. Oden, J. Sjölen, and L. Karlsson, J. Vac. Sci. Technol. A 20, 1815 (2002).

[17] S. PalDey and S. Deevi, Mater. Sci. Eng. A 342, 58 (2003).

[18] D. McIntyre, J. E. Greene, G. Håkansson, J. E. Sundgren, and W.-D. Münz, J. Appl. Phys. 67, 1542 (1990).

[19] P. H. Mayrhofer, A. Hörling, L. Karlsson, J. Sjölén, T. Larsson, C. Mitterer, and L. Hultman, Appl. Phys. Lett. 83, 2049 (2003).

[20] A. Hörling, L. Hultman, M. O. J. Sjölen, and L. Karlsson, Surf. Coat. Technol. 191, 384 (2005).

[21] B. Alling, A. V. Ruban, A. Karimi, O. E. Peil, S. I. Simak, L. Hultman, and I. A. Abrikosov, Phys. Rev. B 75, 045123 (2007).

[22] B. Alling, A. V. Ruban, A. Karimi, L. Hultman, and I. A. Abrikosov, Phys. Rev. B 83, 104203 (2011).

[23] P. H. Mayrhofer, D. Music, and J. Schneider, J. Appl. Phys. 100, 094906 (2006).

[24] B. Alling, A. Karimi, and I. A. Abrikosov, Surf. Coat. Technol. 203, 883 (2008).

[25] D. Holec, R. Rachbauer, D. Kiener, P. D. Cherns, P. M. F. J. Costa, C. McAleese, P. H. Mayrhofer, and C. J. Humphreys, Phys. Rev. B 83, 165122 (2011).

[26] J. L. Endrino, C. Århammar, A. Gutiérrez, R. Gago, D. Horwat, L. Soriano, G. Fox-Rabinovich, D. M. y Marero, J. Guo, J.-E. Rubensson, and J. Andersson, Acta Mater. 59, 6287 (2011).

[27] F. Tasnádi, M. Odén, and I. A. Abrikosov, Phys. Rev. B 85, 144112 (2012).

[28] O. Banakh, M. Balzer, M. Fenker, and A. Blatter, Thin Solid Films 455-456, 650 (2004).

[29] M. Fenker, M. Balzer, H. Kappl, and O. Banakh, Surf. Coat. Technol. 200, 227 (2005).

[30] M. Fenker, M. Balzer, and H. Kappl, Thin Solid Films 515, 27 (2006).

[31] A. Hodroj, O. Chaix-Pluchery, P. Steyer, and J. F. Pierson, Surf. Coat. Technol. 205, 4547 (2011).
[32] S. Onder, F. N. Kok, K. Kazmanli, and M. Urgen, Mater. Sci. Eng. C 33, 4337 (2013).

[33] S. Kerdsongpanya, N. V. Nong, N. Pryds, A. Zukauskaite, J. Jensen, J. Birch, J. Lu, L. Hultman, G. Wingqvist, and P. Eklund, Appl. Phys. Lett. 99, 232113 (2011).

[34] S. Kerdsongpanya, B. Alling, and P. Eklund, Phys. Rev. B 86, 195140 (2012).

[35] M. Akiyama, T. Kamohara, K. Kano, A. Teshigahara, Y. Takeuchi, and N. Kawahara, Adv. Mater. 21, 593 (2009).

[36] F. Tasnádi, B. Alling, C. Höglund, G. Wingqvist, J. Birch, L. Hultman, and I. A. Abrikosov, Phys. Rev. Lett. 104, 137601 (2010).

[37] A. Droghetti, N. Baadji, and S. Sanvito, Phys. Rev. B 80, 235310 (2009).

[38] P. Villars, A. Prince, and H. Okamoto, Handbook of Ternary Alloy Phase Diagrams (ASM International, Materials Park, $\mathrm{OH}$, 1995), Vol. 9.

[39] P. E. Blöchl, Phys. Rev. B 50, 17953 (1994).

[40] G. Kresse and J. Hafner, Phys. Rev. B 48, 13115 (1993).

[41] G. Kresse and J. Furthmüller, Phys. Rev. B 54, 11169 (1996).

[42] G. Kresse and D. Joubert, Phys. Rev. B 59, 1758 (1999).

[43] J. P. Perdew, K. Burke, and M. Ernzerhof, Phys. Rev. Lett. 77, 3865 (1996).

[44] J. Heyd, G. E. Scuseria, and M. Ernzerhof, J. Chem. Phys. 124, 219906 (2006).

[45] A. Zunger, S. H. Wei, L. G. Ferreira, and J. E. Bernard, Phys. Rev. Lett. 65, 353 (1990).

[46] V. L. Moruzzi, J. F. Janak, and K. Schwarz, Phys. Rev. B 37, 790 (1988).

[47] H. J. Monkhorst and J. D. Pack, Phys. Rev. B 13, 5188 (1976).

[48] S. Hao, B. Delley, S. Veprek, and C. Stampfl, Phys. Rev. Lett. 97, 086102 (2006).

[49] J. M. Sanchez, F. Ducastelle, and D. Gratias, Physica A 128, 334 (1984).

[50] F. Ducastelle and F. Gautier, J. Phys. F 6, 2039 (1976).

[51] A. V. Ruban, S. Shallcross, S. I. Simak, and H. L. Skriver, Phys. Rev. B 70, 125115 (2004).

[52] J. W. D. Connolly and A. R. Williams, Phys. Rev. B 27, 5169 (1983).

[53] N. Metropolis, A. W. Rosenbluth, M. N. Rosenbluth, A. H. Teller, and E. Teller, J. Chem. Phys. 21, 1087 (1953).

[54] Powder Diffraction File, JCPDS International Center for Diffraction Data, Swarthmore, PA, 2010; TiN (38-1420).

[55] E. I. Isaev, S. I. Simak, I. A. Abrikosov, R. Ahuja, Y. K. Vekilov, M. I. Katsnelson, A. I. Lichtenstein, and B. Johansson, J. Appl. Phys. 101, 123519 (2007).

[56] C. Höglund, J. Bareno, J. Birch, B. Alling, Z. Czigány, and L. Hultman, J. Appl. Phys. 105, 113517 (2009).

[57] L. Tsetseris, N. Kalfagiannis, S. Logothetidis, and S. T. Pantelides, Phys. Rev. B 76, 224107 (2007).

[58] B. Alling, A. Karimi, L. Hultman, and I. A. Abrikosov, Appl. Phys. Lett. 92, 071903 (2008).

[59] M. T. Baben, L. Raumann, D. Music, and J. M. Schneider, J. Phys.: Condens. Matter 24, 155401 (2012).

[60] ASM Handbook, Alloy Phase Diagrams, edited by Edward H. Kottcamp and Edward L. Langer (ASM International, Materials Park, OH, 1992), Vol. 3. 
[61] O. Reckeweg and F. J. DiSalvo, Z. Anorg. Allg. Chem. 627, 371 (2001).

[62] Y. Prots, R. Niewa, W. Schnelle, and R. Kniep, Z. Anorg. Allg. Chem. 628, 1590 (2002).

[63] B. Alling, C. Höglund, R. Hall-Wilton, and L. Hultman, Appl. Phys. Lett. 98, 241911 (2011).

[64] Inorganic Crystal Structure Database, http://icsd.fizkarlsruhe.de/icsd/

[65] R. Niewa, D. A. Zherebtsov, W. Schnelle, and F. R. Wagner, Inorg. Chem. 43, 6188 (2004).

[66] P. Eklund, M. Beckers, U. Jansson, H. Högberg, and L. Hultman, Thin Solid Films 518, 1851 (2010).

[67] M. Dahlqvist, B. Alling, and J. Rosén, Phys. Rev. B 81, 220102(R) (2010).

[68] J. C. Schuster and H. Nowotny, J. Mater. Sci. 20, 2787 (1985).
[69] C. Höglund, J. Birch, M. Beckers, B. Alling, Z. Czigány, A. Mücklich, and L. Hultman, Eur. J. Inorg. Chem. 2008, 1193 (2008).

[70] F. Rovere, D. Music, S. Ershov, M. T. Baben, H. G. Fuss, P. H. Mayrhofer, and J. M. Schneider, J. Phys. D: Appl. Phys. 43, 035302 (2010).

[71] D. Holec, R. Rachbauer, L. Chen, L. Wang, D. Luef, and P. H. Mayrhofer, Surf. Coat. Technol. 206, 1698 (2011).

[72] D. L. Price and B. R. Cooper, Phys. Rev. B 39, 4945 (1989).

[73] J. Häglund, A. F. Guillermet, G. Grimvall, and M. Körling, Phys. Rev. B 48, 11685 (1993).

[74] C. Stampfl, W. Mannstadt, R. Asahi, and A. J. Freeman, Phys. Rev. B 63, 155106 (2001).

[75] H. A. Al-Brithen, A. R. Smith, and D. Gall, Phys. Rev. B 70, 045303 (2004). 